Check for updates

Cite this: Phys. Chem. Chem. Phys., 2017, 19, 27694

Received 21st July 2017 Accepted 20th September 2017

DOI: $10.1039 / c 7 c p 04932 c$

rsc.li/pccp

\section{Polycyclic aromatic hydrocarbons as model solutes for carbon nanomaterials in ionic liquids $\dagger$}

\author{
Émilie Bordes, $\ddagger^{\mathrm{a}}$ Anabela J. L. Costa, $\ddagger^{\mathrm{bc}}$ Joanna Szala-Bilnik, ${ }^{a}$ Jean- \\ Michel Andanson, ${ }^{a}$ José M. S. S. Esperança, (D) bc Margarida F. Costa Gomes, (D) a \\ José N. Canongia Lopes (D) ${ }^{d}$ and Agílio A. H. Pádua (D)*a
}

\begin{abstract}
The aim of this work is to understand the details of the interactions of ionic liquids with carbon nanomaterials (graphene and nanotubes) using polyaromatic compounds as model solutes. We have combined the measurements of thermodynamic quantities of solvation with molecular dynamics simulations to provide a microscopic view. The solubility of five polycyclic aromatic hydrocarbons (naphthalene, anthracene, phenanthrene, pyrene and coronene) was determined in seven ionic liquids $\left(\left[\mathrm{C}_{4} \mathrm{C}_{1} \mathrm{im}\right]\left[\mathrm{C}(\mathrm{CN})_{3}\right], \quad\left[\mathrm{C}_{4} \mathrm{C}_{1}\right.\right.$ pyrr $]\left[\mathrm{Ntf} \mathrm{f}_{2}\right], \quad\left[\mathrm{C}_{10} \mathrm{C}_{1} \mathrm{im}\right]\left[\mathrm{Ntf} \mathrm{f}_{2}\right], \quad\left[\mathrm{C}_{2} \mathrm{C}_{1} \mathrm{im}\right]\left[\mathrm{C}(\mathrm{CN})_{3}\right], \quad\left[\mathrm{C}_{2} \mathrm{C}_{1} \mathrm{im}\right]\left[\mathrm{Ntf}{ }_{2}\right], \quad\left[\mathrm{C}_{3} \mathrm{C}_{1}\right.$ pyrr $]\left[\mathrm{N}(\mathrm{CN})_{2}\right]$ and $\left.\left[\mathrm{C}_{4} \mathrm{C}_{1} \mathrm{im}\right]\left[\mathrm{N}(\mathrm{CN})_{2}\right]\right)$ at $298 \mathrm{~K}$. The enthalpies of the dissolution of naphthalene, anthracene and pyrene were measured in four of the ionic liquids. Free energies were estimated from those measurements in order to analyse the entropic or enthalpic contributions to the dissolution process. Molecular dynamics simulations provided solvation free energies that were compared to experimental and structural information. Spatial distributions of solvent ions around the solutes when combined with IR measurements elucidate the structure of solvation environments. Interactions between the imidazolium rings of cations and the $\pi$ system of the solutes have been identified. However, ionic liquids with pyrrolidinium cations appeared as better solvents due to favourable enthalpic contributions compared to imidazolium cations. Long alkyl side chains on cations lead to higher solubility and lower enthalpy of dissolution by creating a "softer" solvation environment. Considering the effect of anions, small and planar anions lead to higher solubilities and lower enthalpies of dissolution of polyaromatic hydrocarbons. These findings provide the design principles based on molecular interactions and the structure of solvation environments to choose or formulate ionic liquids in view of their affinity for carbon nanomaterials.
\end{abstract}

\section{Introduction}

\section{Ionic liquids and carbon nanomaterials}

Solution-based routes offer a number of potential advantages for producing or processing nanomaterials, such as being easy to scale up compared to mechanical routes and fine control of mild chemical conditions. Thus, liquid solvents are worth exploring for the exfoliation, ${ }^{1}$ processing ${ }^{2}$ and chemical modification ${ }^{3}$ of nanomaterials, and particularly of carbon nanomaterials such as graphene. In this context, being able to tune solvent

\footnotetext{
${ }^{a}$ Institut de Chimie de Clermont-Ferrand, CNRS and Université Clermont Auvergne, 24 avenue Blaise Pascal, 63177 Aubière, France. E-mail: agilio.padua@uca.fr

${ }^{b}$ Instituto de Tecnologia Quimica e Biológica António Xavier, Universidade Nova de Lisboa, 2780 - 157 Oeiras, Portugal

${ }^{c}$ LAQV, REQUIMTE, Departamento de Quimica, Faculdade de Ciências e Tecnologia, Universidade Nova de Lisboa, 2829-516 Caparica, Portugal

${ }^{d}$ Centro de Quimica Estrutural, Instituto Superior Técnico, Universidade de Lisboa, Av. Rovisco Pais, 1049-001 Lisboa, Portugal. E-mail: jnlopes@tecnico.ulisboa.pt

$\dagger$ Electronic supplementary information (ESI) available. See DOI: 10.1039/c7cp04932c

\$ These authors contributed equally to this work.
}

properties is essential and ionic liquids ${ }^{4}$ (ILs) offer a versatile platform to design solvent media with the required properties. ILs are composed of large organic cations and organic/inorganic anions that are loosely coordinated and do not crystallize easily because of their asymmetric shape, molecular flexibility or delocalized charge. Typical ions contain a charged group and weakly polar side chains, creating a balance between electrostatic and van der Waals interactions. Ionic liquids being molten salts, their liquid phases have a resilient structure imposed by charge ordering, and because of this strong liquid-phase selforganisation, ${ }^{5}$ it is possible to chemically functionalize the ions, imparting them with the desired solvation properties, without drastically changing their liquid nature. Nonetheless, many physical properties, e.g. viscosity, are affected, thus there is a need for a good understanding of the link between the molecular structure and the solvation or physical properties so that optimum solvents can be identified or synthesised. ILs have been studied as solvents for carbon nanomaterials recently in the context of solvent design for the exfoliation of graphene ${ }^{1,6,7}$ or the preparation of nanotube "buckygels". ${ }^{8-10}$ Another situation in 
which carbon nanomaterials and ILs are combined is in supercapacitors for energy storage, whose performance is based on the electrolytic interface between an electrolyte and a graphitic electrode. ${ }^{11-13}$ ILs are non-volatile, non-flammable, highly concentrated liquid electrolytes, and the structure and dynamics of the interfacial layers depend on the structure and interactions of the ions with the electrode material.

In both examples above (ILs as exfoliation/gel promoters or as electrolytes), there is an evident lack of fundamental knowledge concerning the nature of the interactions between ILs and carbon nanomaterials, and the behaviour at their interfaces. This is a major obstacle to the faster advancement in the rational design of processes and devices involving nanotechnologies, using both top-down approaches (such as exfoliation of graphite to produce graphene) or bottom-up routes to build nano-sized objects starting from molecular building blocks. ${ }^{14}$ In either approach, a major challenge is the description of weak noncovalent interactions. Studying non-covalent interactions and solvation in liquid phases directly with carbon nanotubes or graphene poses difficulties in practice related to the irregularities in size, shape or chirality of the carbon nano-objects. Therefore, our strategy in this work is to study perfectlydefined model compounds in detail. Among the model chemical structures that represent the interactions of $\mathrm{sp}^{2}$-carbon nanomaterials are fullerenes and polycyclic aromatic hydrocarbons (PAHs). ${ }^{15-17}$ These molecular compounds can be obtained pure and, besides their "monodispersity" in size and shape, they are not subject to variability arising from defects or chemical functional groups, which are most likely to be present in graphene flakes or nanotubes. Fullerenes do not possess edges and we have previously studied their solvation in ionic liquids, ${ }^{18}$ which is due to the interactions between the ions and the $\pi$-electron system, including polarization effects. PAHs such as coronene do contain hydrogenated edges (and $\pi$-electron clouds), and these edges are also perfectly characterised, making them ideal to study molecular interactions and structuring effects of liquid solvents near graphene. So, although they are small compared to graphene flakes or nanotubes, the study of PAHs can contribute to the understanding of the interactions of ILs with carbon nanomaterials having extended aromatic systems. Our assumption is that PAHs can be viewed as small versions of graphene basal planes and thus can be considered as models to assess the interactions between different solvents and carbon nano-objects.

\section{A small survey of the literature on ILs, carbon nanomaterials and PAHs}

As mentioned above, ionic liquids are suitable media to disperse nanocarbon materials leading to suspensions or gel. ${ }^{19,20}$ After a first step of dispersion using energy supplied by ultrasound, microwaves ${ }^{9}$ or other techniques, ${ }^{21}$ stabilisation of suspensions or solutions can be accomplished by proper choice of cations and anions, which define the properties of the ionic solvent. This choice of the best ionic liquids has been made largely empirically ${ }^{7}$ or based on surfactant properties. ${ }^{22-24}$ One approach is to choose ionic liquids with surface tensions matching the surface energy of the carbon nanomaterial in order to create a compatible solvent-material pair. ${ }^{6,25}$ However, although arguments based on interfacial or cohesive energies ("like dissolves like") are valid, they do not appear to be the sole descriptors for a good solvent, since many liquids with the right properties turn out to be poor solvents for carbon nanomaterials. ${ }^{26}$ This is also a symptom of insufficient understanding about interactions and ordering at the interface.

Several molecular dynamics (MD) simulation studies of ILs in the interfacial layer with carbon nanomaterials have been published. Considering IL-graphite interactions, simulation studies include the interactions of 1-alkyl-3-methylimidazolium hexafluorophosphate, $\left[\mathrm{C}_{n} \mathrm{C}_{1} \mathrm{im}\right]\left[\mathrm{PF}_{6}\right]$ with $n=1,4,8,12,{ }^{27}$ $N$-methyl- $N$-propylpyrrolidinium bis(trifluoromethanesulfonyl)imide $\left[\mathrm{C}_{3} \mathrm{C}_{1}\right.$ pyr $]\left[\mathrm{Ntf}_{2}\right]^{28}$ and 1-alkyl-3-methyimidazolium bis(trifluoromethanesulfonyl)imide $\left(\left[\mathrm{C}_{n} \mathrm{C}_{1} \mathrm{im}\right]\left[\mathrm{Ntf}_{2}\right]\right) .{ }^{29}$ Some common trends can be summarized as follows: the IL layer in contact with the graphite surface exhibits relatively high mass and electron densities, with solid-like characteristics; density oscillations extend into the bulk up to distances corresponding to around three IL layers; the cations and their alkyl side chains are generally parallel to the graphite surface; and the cations are closer to the graphite surface than the anions. In the $\mathrm{MD}$ simulation studies for $\left[\mathrm{C}_{3} \mathrm{C}_{1} \mathrm{pyr}\right]\left[\mathrm{Ntf}_{2}\right],{ }^{29}$ it can be seen how the composition and the ion orientation in the innermost layer is dependent on the electrode potential applied. Vatamanu and co-workers studied the dependence on the electrode potential of the interfacial structure and differential capacitance for $\left[\mathrm{C}_{n} \mathrm{C}_{1} \mathrm{im}\right]\left[\mathrm{Ntf}_{2}\right]^{29}$ at different graphite electrodes using atomistic simulations. Different kinds of graphite electrodes were tested and revealed that the graphite structure influences the results obtained: for prismatic electrode surfaces, counterion accumulation is faster and ion segregation is more important in the interfacial layer. Huo et al. ${ }^{30}$ investigated the cylindrical interface by molecular dynamics simulation between 1-butyl-3methylimidazolium tetrafluoroborate $\left[\mathrm{C}_{4} \mathrm{C}_{1} \mathrm{im}\right]\left[\mathrm{BF}_{4}\right]$ and long armchair single-walled carbon nanotubes (SWNTs) and similar results have been observed for graphite. The simulation results show two dense layers of both IL ions along the normal to the surface of the SWNT and also two different orientation patterns of the cations in the first layer. The fluid dynamics of ILs inside carbon nanopores was tested by Goufi et al. ${ }^{31}$ by molecular simulation. The results showed relatively high diffusion rates of the confined ILs. Such fast diffusion rates are caused by the combination of various factors such as low friction, molecular stacking, size, helicity, curvature and cooperative dynamics effects and are not directly related to possible $\pi-\pi$ interactions since confined ILs based on aliphatic cations such as tetra-alkylammonium also exhibit fast diffusion rates. Finally, onion-like carbon materials (OLCs), composed of concentric graphene-like shells were simulated in a $\left[\mathrm{C}_{2} \mathrm{C}_{1} \mathrm{im}\right]\left[\mathrm{Ntf}_{2}\right]$ IL solvent. ${ }^{32}$

As mentioned in the previous sub-section of this introduction, ILs have been studied as solvents to exfoliate graphite and stabilise graphene in suspension. ${ }^{9,33,34}$ ILs composed of imidazolium cations functionalized with one or two phenyl groups, combined with bis(trifluoromethylsulfonyl)imide anions, were found to be the most effective to stabilise graphene in high 
concentrations. $^{33,34}$ Free energies calculated by molecular dynamics simulations have contributed to understanding the mechanism of graphene exfoliation in ILs. ${ }^{35}$ It was shown that alkyl- $\pi$ interactions predominate in imidazolium and pyrrolidinium ILs, whereas for pyridinium ILs $\pi-\pi$ interactions with the graphene surface dominate. Spectroscopic data confirmed the simulation results showing that the alkyl chain groups of the ionic liquids are located along the surface of graphene. ${ }^{36}$ A few years before the surge of interest in graphene, some studies focused on gel-like materials formed by carbon nanotubes (CNTs) in ILs. ${ }^{37,38}$ The interaction between imidazolium ILs and carbon nanotubes does not seem to be governed by $\pi-\pi$ interactions but instead by weak van der Waals interactions that induce a shielding effect disrupting the stacking interaction. The ordering of ionic liquids is not altered according to Wang et al. ${ }^{39}$ suggesting that these fluids might be a promising dispersion media for CNTs.

ILs are also potential separation/extraction media for several different kinds of compounds, ${ }^{40,41}$ including PAHs, ${ }^{42-46}$ which are referred to as persistent organic pollutants due to their increasing bioaccumulation, possible chemical transformation and high toxicity. An IL-based technology can also be used to design special HPLC columns to separate PAH chiral compounds. ${ }^{47}$ Various studies of PAHs in IL solutions have been reported, mainly in the scope of extraction applications, such as microextraction, ${ }^{48-53}$ analytical techniques ${ }^{54}$ such as chromatography ${ }^{55-57}$ or environmental issues. ${ }^{56,58}$ In microextraction processes, ILs act as fiber modifiers and the resulting materials are used to extract PAH analytes with higher resolution. In chromatography techniques, ILs can be used as additives in both the stationary or mobile phases. Their uses in chromatography techniques increase the specificity and selectivity of those methods. Considering environmental issues, Liu et al. ${ }^{58}$ and Maszkowska et $a{ }^{56}{ }^{56}$ studied the behaviour of imidazolium, pyridinium, pyrrolidinium, phosphonium, and morpholinium ILs with hexafluorophosphate, tetracyanoborate and bis(trifluoromethylsylfonyl)imide anions as extractants for different PAHs from aqueous solutions. Tetracyanoborate-based ILs were found to be the best extractants for PAHs dissolved in water, especially for low-molecularweight species like phenanthrene or fluoranthene.

Wagle et $a l .{ }^{59}$ tried to elucidate the interactions between ILs and PAHs by quantum chemical calculations. They concluded that all the cations interact with the negative electrostatic surface of the PAHs, situated above and below the plane of the aromatic rings while the alkyl side chains on the cations distribute in the voids and form non-polar domains. Stronger binding energies were found for the imidazolium-based ILs, with more negative binding enthalpies being calculated for the heavier PAHs at lower temperatures. However, these calculations were performed in isolated species in a vacuum, without representation of explicit solvation in a condensed IL phase. Moreover, by comparing the surface potential drop across the interfacial region for $\left[\mathrm{C}_{4} \mathrm{C}_{1} \mathrm{im}\right]\left[\mathrm{PF}_{6}\right]$ and $\left[\mathrm{C}_{8} \mathrm{C}_{1} \mathrm{im}\right]\left[\mathrm{PF}_{6}\right]$, it is smaller for $\left[\mathrm{C}_{4} \mathrm{C}_{1} \mathrm{im}\right]\left[\mathrm{PF}_{6}\right]$ because in the interfacial region, the anions with relatively smaller volume have higher density than the cations, decreasing the potential for ILs with smaller alkyl side chains in the cation.
In this work, we aim to study the solvation of PAHs in carefully chosen ILs, combining experimental thermodynamics of solvation data with a microscopic interpretation obtained using molecular dynamics simulation of the solutions. For a detailed study of physical chemistry, we focused on three PAHs naphthalene, anthracene and pyrene - dissolved in ILs with varying cation head groups, alkyl side chains and anions, in order to identify the relations between chemical structure, interactions and solvation thermodynamics.

\section{Experimental methods}

The experimental part of this work includes the solubility measurements at room temperature of different PAHs in IL solutions, the determination of the enthalpies of dissolution in some of these solutions, and recording of additional vibrational spectroscopy data. The computational part includes the modelling and molecular dynamics simulations of relevant PAH/IL solutions in order to achieve their characterisation in terms of the structure and interactions at a molecular level.

\section{Materials}

Chemical compounds used for the solubility measurements were naphthalene (99.6\%, Alfa Aesar), anthracene (99\%, Acros Organics), phenanthrene (98\%, Alfa Aesar), pyrene (98\%, Alfa Aesar) and coronene (>95\%, Tokyo Chemical Industry). For other measurements, the chemical compounds (Fig. 1) used
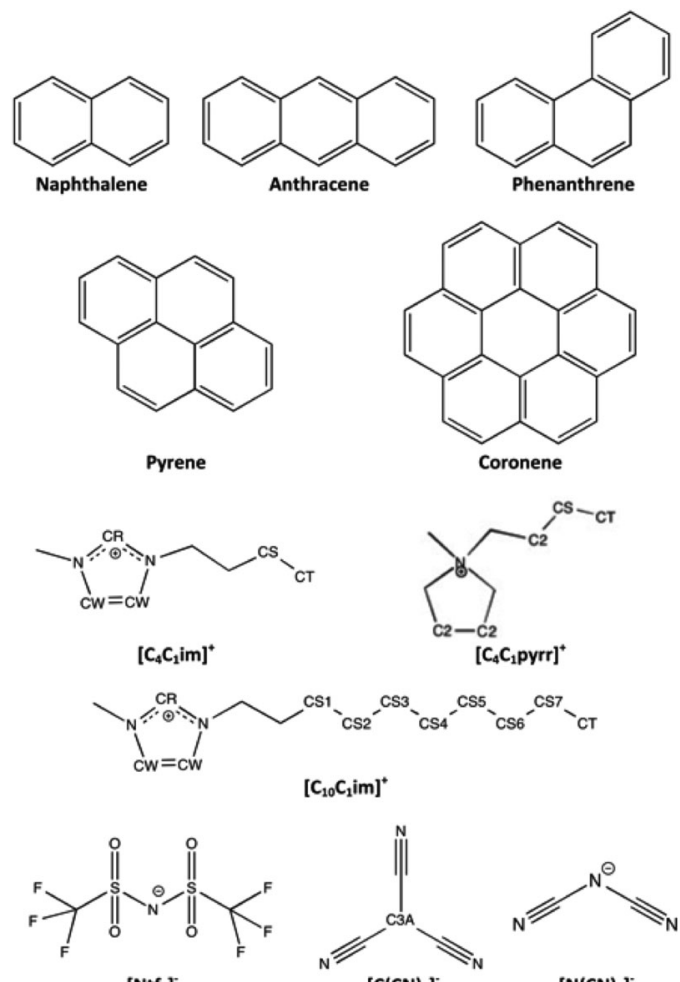

$\left[\mathrm{Ntf}_{2}\right]$

$\left[\mathrm{C}(\mathrm{CN})_{3}\right]^{\cdot}$

$\left[\mathrm{N}(\mathrm{CN})_{2}\right]$

Fig. 1 Chemical structure of the five PAH solutes and selected IL ions studied in this work, including acronyms for the atom types defined in the molecular force field used to model the different ionic liquids. 
were naphthalene (99.6\%), anthracene (99\%) and pyrene (98\%) from Alfa Aesar, ground and sifted under $100 \mu \mathrm{m}$ to obtain uniform powder. The four ionic liquids chosen for dissolution calorimetry and infrared (IR) spectroscopy are composed of imidazolium or pyrrolidinium cations combined with bis(trifluorosulfonyl)amide, $\left[\mathrm{Ntf}_{2}\right]^{-}$, and tricyanomethanide, $\left[\mathrm{C}(\mathrm{CN})_{3}\right]^{-}$, anions. Specifically, the ILs 1-butyl-3-methylimidazolium bis(trifluorosulfonyl)amide, $\left[\mathrm{C}_{4} \mathrm{C}_{1} \mathrm{im}\right]\left[\mathrm{Ntf}_{2}\right](99 \%)$, 1-decyl-3-methylimidazolium bis(trifluorosulfonyl)amide, $\left[\mathrm{C}_{10} \mathrm{C}_{1} \mathrm{im}\right]\left[\mathrm{Ntf}_{2}\right](98 \%)$, butylmethylpyrrolidinium bis(trifluorosulfonyl)amide, $\quad\left[\mathrm{C}_{4} \mathrm{C}_{1}\right.$ pyrr $]\left[\mathrm{Ntf}_{2}\right]$ (99\%), and 1-butyl-3-methylimidazolium tricyanomethanide, $\left[\mathrm{C}_{4} \mathrm{C}_{1} \mathrm{im}\right]\left[\mathrm{C}(\mathrm{CN})_{3}\right](98 \%)$, were purchased from Iolitec. The ILs were dried under vacuum for $72 \mathrm{~h}$ reaching a water content below $100 \mathrm{ppm}$. Benzene, acetonitrile and $n$-decane were purchased from Aldrich (HPLC grade) and tetrachloromethane from Acros Organics (99\%).

\section{Solubility}

High-performance liquid chromatography was performed using a photodiode array UV-Vis detector (HPLC-DAD) combined with a quaternary pump and a C8 reverse-phase column. Acetonitrile/ water was used as the isocratic eluent to measure the concentration of PAHs in IL solutions. Different experimental conditions were tested to define the best set of parameters for each $\mathrm{PAH}$. Several acetonitrile solutions with fixed PAH concentration were used to perform the calibration curves. The conditions used in the HPLC-DAD runs are given in Table 1. To measure the solubility of PAHs in different ILs, we prepared saturated solutions by adding an amount of PAH above the solubility limit. The solution was left stirring for 3 days to achieve the solubility limit. The mixture was then centrifuged and the solid was separated from the liquid. This liquid sample was prepared with acetonitrile and the sample was injected in the apparatus. A calibration curve was used to calculate the amount of PAHs dissolved in the ILs. All measurements were performed at $298 \mathrm{~K}$. Multiple independent samples (3 to 5 repetitions) were used in order to obtain statistically meaningful results.

\section{Dissolution calorimetry}

The heat of dissolution of crystalline PAHs in different ILs was studied using an isoperibol solution calorimeter (SolCal from TA Instruments) housed in a TAM-III thermostat. Glass ampoules with a volume of $1.1 \mathrm{~mL}$ were filled gravimetrically with 0.03 to $0.1 \mathrm{~g}$ of PAHs and sealed with a rubber stopper and wax. Once sealed, an ampoule is loaded into the calorimeter vessel containing $25 \mathrm{~mL}$ of $\mathrm{IL}$ and allowed to equilibrate in the thermostat for circa four hours, under stirring at $500 \mathrm{rpm}$.
The ampoule is then crushed against a sapphire tip and the solute starts dissolving inducing a change in the temperature of the mixing vessel with respect to the surrounding thermostat, which is kept at the set temperature. When the dissolution of PAHs is complete and the baseline temperature is recovered (about three hours), an electrical heat pulse of $10 \mathrm{~J}$ is applied for calibration. Because the dissolution is slow when compared to the thermal relaxation time of the calorimeter itself, the temperature profiles of the experiments were modelled using a suitable working equation as described previously. ${ }^{60}$

$$
T(t)=\frac{n_{0} \Delta H}{C_{\mathrm{p}}} \frac{\tau_{\mathrm{c}}}{\tau_{\mathrm{c}}-\tau_{\mathrm{d}}}\left(\mathrm{e}^{-t / \tau_{\mathrm{c}}}-\mathrm{e}^{-t / \tau_{\mathrm{d}}}\right)+T_{\infty}
$$

where $\tau_{\mathrm{d}}$ and $\tau_{\mathrm{c}}$ are the time constants of the dissolution process and of thermal relaxation of the calorimeter, respectively; $T_{\infty}$ is the temperature when the calorimeter is in equilibrium with its surrounding thermostat; $C_{\mathrm{p}}$ is the heat capacity of the mixing vessel and $\Delta H$ is the negative enthalpy of dissolution. Dissolution experiments were repeated for each system at least three times above room temperature (at $318 \mathrm{~K}$ ) in order to accelerate the dissolution process in the relatively viscous ionic liquids.

\section{IR measurements}

An FTIR (Fourier Transform Infrared) Nicolet 380 Smart Orbit Thermoscientific spectrometer equipped with an ATR (Attenuated Total Reflectance) diamond cell was used to record infrared spectra. Each spectrum was obtained at a resolution of $1 \mathrm{~cm}^{-1}$ with the co-addition of 128 scans, except for carbon tetrachloromethane $\left(\mathrm{CCl}_{4}\right)$ with 64 scans. All spectra were recorded in the range of $400-4000 \mathrm{~cm}^{-1}$. With anthracene, the solubility in the ionic liquids was quite low and therefore the signal-to-noise ratio was improved by decreasing the resolution to $4 \mathrm{~cm}^{-1}$.

\section{Molecular simulations}

The PAHs were represented by the OPLS-AA force field for aromatic compounds, ${ }^{61}$ and the ionic liquids were represented using the force field of Canongia Lopes and Pádua. ${ }^{62,63}$ Atomic partial charges in the ions were scaled by a factor of 0.8 , which leads to an improved representation of dynamic and solvation properties. ${ }^{64-66}$ Simulation boxes containing 100 ion pairs and one solute molecule were prepared using the $\mathrm{fftool}^{67}$ and $\mathrm{Packmol}^{68}$ tools. Molecular dynamics simulations were performed using the LAMMPS ${ }^{69}$ code, with a timestep of $1 \mathrm{fs}$, a cutoff of $12 \AA$ for the Lennard-Jones interactions, and electrostatic interactions calculated with a relative precision of $10^{-4}$ using the particleparticle/particle-mesh method. The initial configurations were

Table 1 Experimental conditions used in the HPLC-DAD runs

\begin{tabular}{lllll}
\hline Compounds & $\mathrm{H}_{2} \mathrm{O}:$ ACN eluent-flow & $\lambda(\mathrm{nm})$ & $V_{\text {injection }}(\mathrm{mL})$ & Calibration intervals $\left(\mathrm{mg} \mathrm{L}^{-1}\right)$ \\
\hline Naphthalene & $35: 65-0.8 \mathrm{~mL} \mathrm{~min}^{-1}$ & 219 & 5 & $8.00-102.2$ \\
Anthracene & $25: 75-1.0 \mathrm{~mL} \mathrm{~min}^{-1}$ & 252 & 5 & $9.72-82.78$ \\
Phenanthrene & & 252 & 8 & $3.59-90.54$ \\
Pyrene & $15: 85-0.8 \mathrm{~mL} \mathrm{~min}^{-1}$ & 240 & 5 & $2.90-76.42$ \\
Coronene & 302 & 60 & $0.17-3.54$
\end{tabular}


equilibrated at $343 \mathrm{~K}$ and 1 bar, maintained by Nosé-Hoover integrators. A working temperature above room temperature was chosen in order to improve the fluidity of the ionic liquid leading to shorter simulation times. The chemical potential of PAH in the ionic liquids was calculated by the free energy perturbation (FEP) method, implemented using the USER-FEP package available in LAMMPS. One solute molecule, naphthalene in this study, was progressively activated in a simulation box containing the IL solvent by means of a coupling parameter $\lambda$ that affected the solute-solvent interactions (Lennard-Jones pair terms and Coulomb charges on the solute). At $\lambda=0$, one solute is present in the simulation box but does not interact with the solvent. At $\lambda=1$, the solute interacts fully with the solvent. The path between these endpoints was sampled in 40 intervals (stages) using the FEP technique. At each value of the activation parameter, the system was equilibrated for $600 \mathrm{ps,} \mathrm{after} \mathrm{which} \mathrm{time,} \mathrm{the} \mathrm{free} \mathrm{energy}$ difference between two successive $\lambda$ points is sampled for $1.4 \mathrm{~ns}$. Both the "creation" and "annihilation" routes were computed to make sure hysteresis is negligible. In order to avoid singularities when the solute couples or uncouples with the solvent (near $\lambda=0$ ), soft-cored potentials ${ }^{70}$ were used. Example curves are shown in Fig. S3.1 in the ESI. $\dagger$ The chemical potential difference associated with the activation of the solute, $\Delta \mu$, was calculated from eqn (2), where $i$ is the number of stages.

$$
\Delta \mu=-k T \sum_{i=0}^{i-1} \ln \left\langle\exp \left(-\frac{U_{\lambda_{i+1}}-U_{\lambda_{i}}}{k T}\right)\right\rangle
$$

Naphthalene was activated ex nihilo in each solvent concomitantly, the same free energy route was followed with an isolated naphthalene molecule (in a vacuum), in order to account for the contribution of intramolecular terms to the chemical potential. The thermodynamic cycle used to arrive at the residual chemical potential, $\mu^{\text {res }}$, is presented in Fig. 2. As a result, the computed chemical potential $\mu^{\text {res }}$ corresponds to the free energy of transfer of the PAHs from an ideal gas state to a dilute solution, at constant temperature and volume (or solute density). The solubility of the PAHs in ILs was calculated from eqn (3):

$$
x=\frac{p^{*}}{\rho_{\mathrm{IL}} R T} \exp \left(-\frac{\mu^{\mathrm{res}}}{R T}\right)
$$

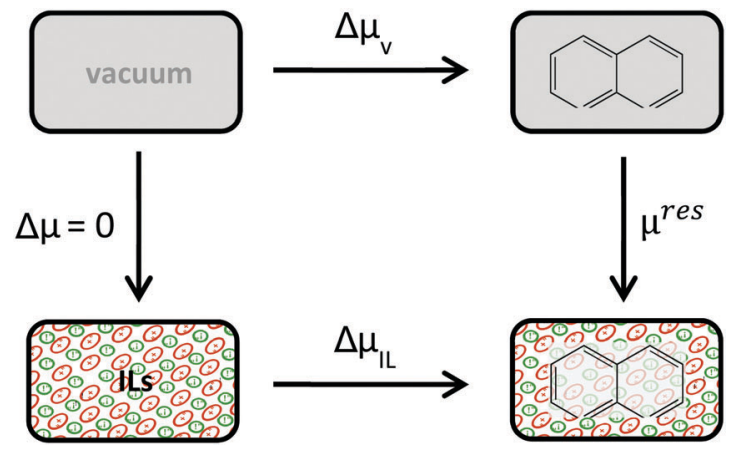

Fig. 2 Thermodynamic cycle used to calculate the residual chemical potential.
This equation is implicit in the definition of free energy of solvation, thus $\rho_{\mathrm{IL}}$ is the molar density of the IL solvent and $p^{*}$ is the saturation pressure of the (solid) PAH solute.

In order to analyse the structure of the solvation shells formed by the different ionic liquids around naphthalene, radial and spatial distribution functions were calculated from simulation trajectories. The spatial distribution plots contain isodensity surfaces at twice the average number density of the specific solvent atoms in the systems.

\section{Results and discussion}

\section{Solubility of PAHs in IL solutions}

The solubility limits of five PAHs (naphthalene, anthracene, phenanthrene, pyrene and coronene) were measured in seven different ILs at $298 \mathrm{~K}$. The corresponding solubility data are reported in Tables S1.1-S1.3 of the ESI $\dagger$ and represented in Fig. 3. The data show that the solubility of the PAH solutes in the different IL solvents spans almost four orders of magnitude and is mainly determined by the nature of the PAH. Naphthalene and phenanthrene are the most soluble in all ILs, followed by pyrene, anthracene and coronene. Interestingly, phenanthrene is almost two orders of magnitude more soluble in ILs than its isomer anthracene. Such a fact can be explained taking into consideration the relative stabilities of the crystalline forms of the two PAHs: the melting temperature (490 K), the enthalpy of fusion at that temperature $\left(29 \mathrm{~kJ} \mathrm{~mol}^{-1}\right)$ and the enthalpy of sublimation at $298 \mathrm{~K}\left(98 \mathrm{~kJ} \mathrm{~mol}^{-1}\right)$ are much larger than the corresponding values for phenanthrene $\left(370 \mathrm{~K}, 16 \mathrm{~kJ} \mathrm{~mol}^{-1}\right.$ and $91 \mathrm{~kJ} \mathrm{~mol}^{-1}$, respectively). Moreover, naphthalene is clearly an outlier when one tries to correlate the crystal-related thermophysical properties with PAH size. In this context it is worth mentioning that it is easier to dissolve pyrene than anthracene in all tested IL solvents.

Concerning the effect of the IL solvents on the PAH solubility values, all five PAHs are in general more soluble in $\left[\mathrm{C}_{4} \mathrm{C}_{1} \mathrm{im}\right]\left[\mathrm{C}(\mathrm{CN})_{3}\right]$ and $\left[\mathrm{C}_{10} \mathrm{C}_{1} \mathrm{im}\right]\left[\mathrm{Ntf}_{2}\right]$. For naphthalene and phenanthrene,

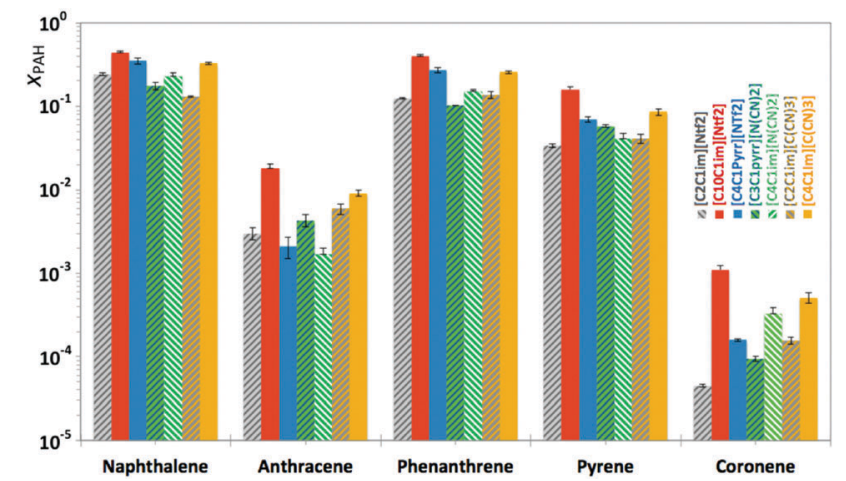

Fig. 3 Solubility of five PAHs in seven different ILs at room temperature. All data are expressed in $\mathrm{PAH}$ mole fraction, $\mathrm{X}_{\mathrm{PAH}}$, in a logarithmic scale: $\left[\mathrm{C}_{2} \mathrm{C}_{1}\right.$ im] $\left[\mathrm{Ntf}_{2}\right]$ - grey-striped bars; $\left[\mathrm{C}_{10} \mathrm{C}_{1} \mathrm{im}\right]\left[\mathrm{Ntf}_{2}\right]$ - red bars; $\left[\mathrm{C}_{4} \mathrm{C}_{1}\right.$ pyrr] $\left[\mathrm{Ntf}_{2}\right]$ - blue bars; $\left[\mathrm{C}_{3} \mathrm{C}_{1}\right.$ pyrr] $\left[\mathrm{N}(\mathrm{CN})_{2}\right]$ - dark green striped bars; $\left[\mathrm{C}_{4} \mathrm{C}_{1}\right.$ im] $\left[\mathrm{N}(\mathrm{CN})_{2}\right]$ - light green striped bars; $\left[\mathrm{C}_{2} \mathrm{C}_{1}\right.$ im] $\left[\mathrm{C}(\mathrm{CN})_{3}\right]$ - yellow striped bars; $\left[\mathrm{C}_{4} \mathrm{C}_{1} \mathrm{im}\right]\left[\mathrm{C}(\mathrm{CN})_{3}\right]$ - yellow bars. 
$\left[\mathrm{C}_{4} \mathrm{C}_{1}\right.$ pyrr $]\left[\mathrm{Ntf}_{2}\right]$ also exhibits relatively high solubility values. Conversely, the ILs with the lowest PAH solubility are $\left[\mathrm{C}_{2} \mathrm{C}_{1} \mathrm{im}\right]\left[\mathrm{C}(\mathrm{CN})_{3}\right]$ for naphthalene, $\left[\mathrm{C}_{4} \mathrm{C}_{1}\right.$ pyrr $]\left[\mathrm{Ntf}_{2}\right]$ for anthracene and $\left[\mathrm{C}_{2} \mathrm{C}_{1} \mathrm{im}\right]\left[\mathrm{Ntf}_{2}\right]$ for the remainder three PAHs. Based on these results, the ILs chosen for further studies were $\left[\mathrm{C}_{4} \mathrm{C}_{1} \mathrm{im}\right]\left[\mathrm{C}(\mathrm{CN})_{3}\right],\left[\mathrm{C}_{10} \mathrm{C}_{1} \mathrm{im}\right]\left[\mathrm{Ntf}_{2}\right]$ and $\left[\mathrm{C}_{4} \mathrm{C}_{1} \mathrm{pyrr}\right]\left[\mathrm{Ntf}_{2}\right]$.

Comparisons of the three ILs with $\left[\mathrm{C}_{4} \mathrm{C}_{1} \mathrm{im}\right]\left[\mathrm{Ntf}_{2}\right]$ allow analyses in terms of anion substitution, alkyl side chain extension and cation exchange effects, respectively.

\section{Thermodynamics of dissolution}

The enthalpies of dissolution measured for the different PAHs in ILs are presented in Fig. 4 (the experimental enthalpy values are reported in the ESI, $\dagger$ Table S2.1). Due to the reduced number of repetitions, the statistical uncertainty of the measured enthalpies of dissolution was estimated by Student's t-distribution (95\% confidence interval) for each different IL, leading to an overall uncertainty of $9 \%$. Dissolution is endothermic in all cases, with a higher positive enthalpy of dissolution for anthracene, followed by naphthalene and then pyrene. The enthalpy of dissolution depends not only on solute-solvent interactions but also on the cohesive energy of the solid, which may be the dominant effect distinguishing the three PAHs. It appears that the enthalpies of dissolution are higher in $\left[\mathrm{C}_{4} \mathrm{C}_{1} \mathrm{im}\right]\left[\mathrm{Ntf}_{2}\right]$ and tend to be lower in the ionic liquid with a long alkyl chain, $\left[\mathrm{C}_{10} \mathrm{C}_{1} \mathrm{im}\right]\left[\mathrm{Ntf}_{2}\right]$, but also in $\left[\mathrm{C}_{4} \mathrm{C}_{1} \mathrm{im}\right]\left[\mathrm{C}(\mathrm{CN})_{3}\right]$, which has a planar anion.

Evaluation of the entropy of dissolution leads to a more complete understanding of the thermodynamics of the dissolution process. This is possible if we estimate the free energy of dissolution from the solubility $x$ (assuming, as an approximation, unitary activity coefficients) and then deducing the entropic term, eqn (4):

$$
\Delta G_{\mathrm{dis}}=\Delta H_{\mathrm{diss}}-T \Delta S_{\mathrm{diss}} \approx-R T \ln (x)
$$

Table 2 summarizes the analysis of the enthalpic and entropic effects by comparing and identifying the pairs of IL solvents that are more favourable (in the case of $\left[\mathrm{C}_{4} \mathrm{C}_{1} \mathrm{im}\right]\left[\mathrm{Ntf}_{2}\right]$, the solubility was not measured, but rather calculated by an interpolation using the solubility values of $\left[\mathrm{C}_{2} \mathrm{C}_{1} \mathrm{im}\right]\left[\mathrm{Ntf}_{2}\right]$ and $\left.\left[\mathrm{C}_{10} \mathrm{C}_{1} \mathrm{im}\right]\left[\mathrm{Ntf}_{2}\right]\right)$.

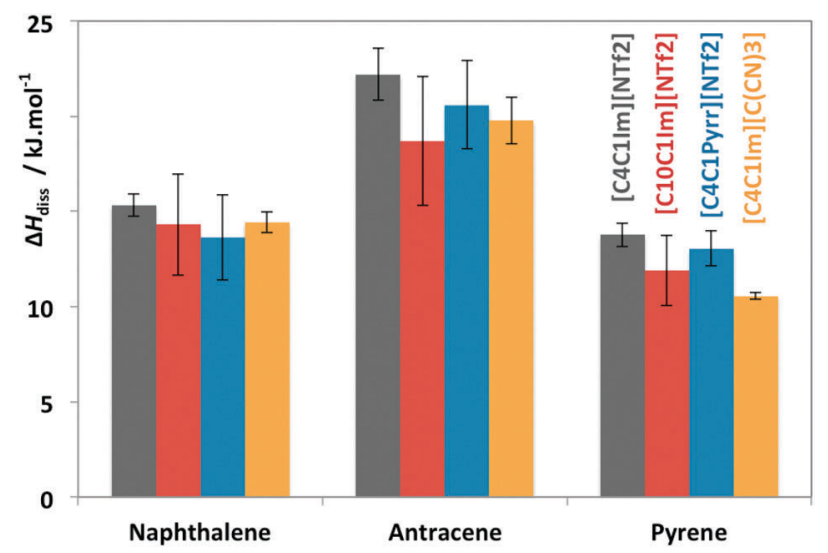

Fig. 4 Experimental enthalpy of dissolution values, $\Delta H_{\text {diss, }}$ of three PAHs in four ILs at $298 \mathrm{~K}$.
Table 2 Enthalpic, $\Delta H$, and entropic, $T \Delta S$, contributions to the free energy of dissolution, $\Delta G$, at $298 \mathrm{~K}$ of $\mathrm{PAHs}$ in ionic liquids. The three pairs of rows compare alkyl side chain, anion and cation head-group effects within the IL pairs. $\left[\mathrm{C}_{4} \mathrm{C}_{1} \mathrm{im}\right]\left[\mathrm{Ntf}_{2}\right]$ is used as a common reference IL. The bold values correspond to favourable contributions to the dissolution of a given $\mathrm{PAH}$ for a particular IL pair

\begin{tabular}{|c|c|c|c|c|c|c|c|c|c|}
\hline \multirow[b]{2}{*}{ ILs } & \multicolumn{3}{|c|}{ Naphthalene } & \multicolumn{3}{|c|}{ Anthracene } & \multicolumn{3}{|c|}{ Pyrene } \\
\hline & $\Delta H$ & $T \Delta S$ & $\Delta G$ & $\Delta H$ & $T \Delta S$ & $\Delta G$ & $\Delta H$ & $T \Delta S$ & $\Delta G$ \\
\hline$\left[\mathrm{C}_{10} \mathrm{C}_{1} \mathrm{im}\right]\left[\mathrm{Ntf}_{2}\right]$ & 14 & 12 & 2 & 18 & 8 & 10 & 12 & 7 & 5 \\
\hline$\left[\mathrm{C}_{4} \mathrm{C}_{1} \mathrm{im}\right]\left[\mathrm{Ntf}_{2}\right]$ & 15 & 12 & 3 & 22 & 10 & 12 & 14 & 7 & 7 \\
\hline$\left[\mathrm{C}_{4} \mathrm{C}_{1} \mathrm{im}\right]\left[\mathrm{C}(\mathrm{CN})_{3}\right]$ & 14 & 11 & 3 & 19 & 7 & 12 & 11 & 5 & 6 \\
\hline$\left[\mathrm{C}_{4} \mathrm{C}_{1} \mathrm{im}\right]\left[\mathrm{Ntf}_{2}\right]$ & 15 & 12 & 3 & 22 & 10 & 12 & 14 & 7 & 7 \\
\hline$\left[\mathrm{C}_{4} \mathrm{C}_{1}\right.$ pyrr $]\left[\mathrm{Ntf}_{2}\right]$ & 13 & 10 & 3 & 21 & 6 & 15 & 13 & 6 & 7 \\
\hline$\left[\mathrm{C}_{4} \mathrm{C}_{1} \mathrm{im}\right]\left[\mathrm{Ntf}_{2}\right]$ & 15 & 12 & 3 & 22 & 10 & 12 & 14 & 7 & 7 \\
\hline
\end{tabular}

The data in the first two rows of Table 2 show that PAH dissolution in ILs composed of imidazolium cations with a longer alkyl chain yields lower free energy of dissolution values.

Such more favourable processes are the result of less endothermic enthalpic contributions. This agrees with the observations in the literature ${ }^{59}$ concerning the affinity between alkyl side chains in imidazolium cations and PAHs.

The third and fourth rows analyse the effect of anion replacement. The results show that $\mathrm{PAH}$ dissolutions in a $\left[\mathrm{Ntf}_{2}\right]$ based IL are entropically more favourable than PAH dissolutions in a $\left[\mathrm{C}(\mathrm{CN})_{3}\right]$-based IL. The reverse is true from the enthalpic contribution point of view ( $c f$. Tables S2.1 and S2.2, ESI $\dagger$ ). In most cases, the two contributions cancel each other and lead to similar $\mathrm{PAH}$ solubilities in the two ILs. In the case of pyrene, PAH dissolution appears to be dominated by the enthalpic term leading to a higher pyrene solubility in the $\left[\mathrm{C}(\mathrm{CN})_{3}\right]$-based IL. The fifth and sixth rows compare the role of IL aromaticity in PAH dissolution by confronting imidazolium- and pyrrolidinium-based cations. Again, there are opposing contributions from the enthalpic and entropic terms, which lead to similar PAH dissolution free energies in most cases. The exception in this case is the dissolution of anthracene, which is more favourable in the imidazolium-based IL and is controlled by a more favourable entropic contribution.

The solubility of naphthalene in the same four ionic liquids was estimated from simulation, via the residual chemical potential $\mu^{\text {res }}$. The results are presented in Table 3, where it can be seen that the highest solubility was obtained for $\left[\mathrm{C}_{10} \mathrm{C}_{1} \mathrm{im}\right]\left[\mathrm{Ntf}_{2}\right]$, which is the $\mathrm{IL}$ with a longer alkyl chain. The solubility of naphthalene is greater in $\left[\mathrm{C}_{4} \mathrm{C}_{1}\right.$ pyrr $]\left[\mathrm{Ntf}_{2}\right]$ than in $\left[\mathrm{C}_{4} \mathrm{C}_{1} \mathrm{im}\right]\left[\mathrm{Ntf}_{2}\right]$, and the lowest value was found to be for dissolution in $\left[\mathrm{C}_{4} \mathrm{C}_{1} \mathrm{im}\right]\left[\mathrm{C}(\mathrm{CN})_{3}\right]$. Although the simulation results are not in quantitative agreement with experimental $x_{\exp }$ values (also shown in Table 3), the corresponding solubility trends are in full accord with those of the calorimetric and solubility experiments. These results of solubility by FEP calculation validate the ability of the present force fields and molecular dynamics methods to capture the essential molecular features determining solubility.

\section{Structural analysis}

The solvation layers of ions around the naphthalene molecules were investigated by calculation of radial distribution functions 
Table 3 Residual chemical potential and the estimated mole fraction solubility of naphthalene in four ILs

\begin{tabular}{lllll}
\hline $\mathrm{ILs}$ & {$\left[\mathrm{C}_{4} \mathrm{C}_{1} \mathrm{im}\right]\left[\mathrm{Ntf}_{2}\right]$} & {$\left[\mathrm{C}_{10} \mathrm{C}_{1} \mathrm{im}\right]\left[\mathrm{Ntf}_{2}\right]$} & {$\left[\mathrm{C}_{4} \mathrm{C}_{1} \mathrm{pyrr}_{[}\right]\left[\mathrm{Ntf}_{2}\right]$} & {$\left[\mathrm{C}_{4} \mathrm{C}_{1} \mathrm{im}\right]\left[\mathrm{C}(\mathrm{CN})_{3}\right]$} \\
\hline$\mu^{\text {res }} / \mathrm{kJ} \mathrm{mol}{ }^{-1}$ & $-21.63 \pm 0.24$ & $-22.22 \pm 0.47$ & $-21.82 \pm 1.15$ & $-21.46 \pm 0.36$ \\
$x_{\text {sim }}$ & 0.10 & 0.16 & 0.11 & 0.07 \\
$x_{\exp }(c f$. Table S1.2, ESI $)$ & - & 0.438 & 0.350 & 0.325
\end{tabular}

(RDFs) between the selected atoms in the IL ions and the two central carbons of naphthalene. RDFs represent the local density of finding a given pair of atomic sites as a function of distance, divided by the average density in the system. In RDFs, information about orientational distribution has been averaged. Spatial distribution functions (SDFs) convey the spatial distribution of chosen sites, i.e. their local density in space, with respect to a central molecule, and are represented in $3 \mathrm{D}$ in the form of isodensity surfaces of the selected atoms of the IL. The naming convention for the IL atom types is given in Fig. 1.

The SDFs presented in Fig. 5 reveal that cations are localised mainly in positions above and below the plane of naphthalene, whereas anions are found predominantly around that plane, close to the hydrogen atoms of the PAH. Analogous ionic arrangements around benzene molecules have been observed in previous studies. ${ }^{59,71,72}$ The imidazolium rings are localised parallel, below and above the plane of naphthalene suggesting strong cation $-\pi$ interactions. Pyrrolidinium cations are also found above and below the aromatic plane. However, the $\mathrm{N}$ atom of pyrrolidinium is found at larger distances from the $\mathrm{PAH}$ solute, when compared to atoms of the imidazolium rings. This is seen in the positions of the first maxima of the corresponding RDFs in Fig. 6, which occur at ca. $3.8 \AA$ for the aromatic carbon atoms of the imidazolium ring and at about $4.8 \AA$ for the nitrogen atom of pyrrolidinium. It is also interesting to note that the neutral alkyl side chains of the pyrrolidinium cations can be found closer to the PAH than the positively charged $\mathrm{N}$ atom (seen in the RDF plot of Fig. $6 \mathrm{~b}$ and in the isodensity surfaces in Fig. 5). As happens with the alkyl chain, the $\mathrm{C} 2$ atoms of the pyrrolidinium ring also tend to be

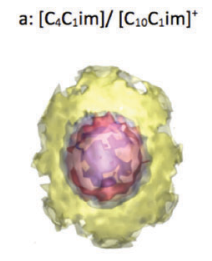

c: $\left[\mathrm{C}_{4} \mathrm{C}_{1} \text { pyrr }\right]^{+}$
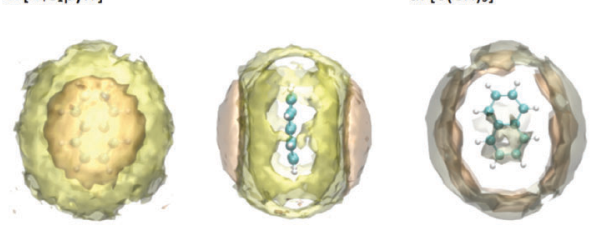
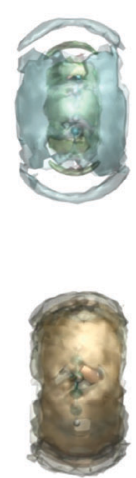

Fig. 5 Spatial distribution functions of selected atoms of the cations and anions around naphthalene. The correspondences of coloured isodensity surfaces to atom types are: (a) CR/CW, red/pink and CT, yellow; (b) N, orange and CT, yellow; (c) O, blue and F, green; (d) N, grey and C3A, tan (atom type acronyms as in Fig. 1).

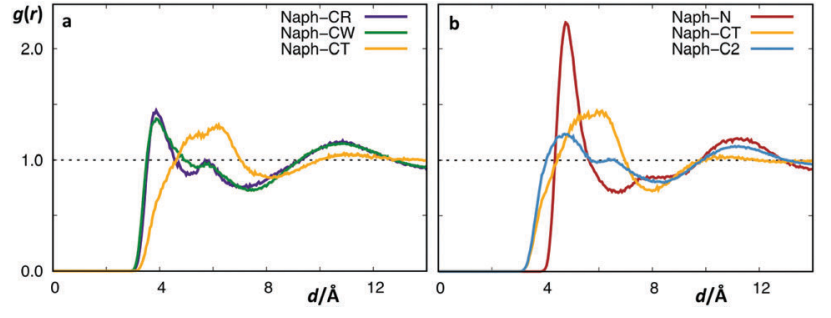

Fig. 6 Radial distribution functions, $g(r)$, between the pairs of selected atoms of the (a) imidazolium and (b) pyrrolidinium cations and the two central carbons of naphthalene (Naph) in [C4C1im][Ntf2] and [C4C1pyrr][Ntf2] ILs. Acronyms as in Fig. 1.

found closer to naphthalene than the positively charged $\mathrm{N}$ chain, the $\mathrm{C} 2$ atoms of the pyrrolidinium ring also tend to be found closer to naphthalene than the positively charged $\mathrm{N}$ atom, which is an interesting aspect of how pyrrolidinium cations are arranged near the aromatic plane. In fact, most PAHs are slightly more soluble in pyrrolidinium than in imidazolium salts with the same side chain $\left(\mathrm{C}_{4}\right)$ and anion $\left(\left[\mathrm{Ntf}_{2}\right]^{-}\right)$. These slight differences are driven by the enthalpic contributions to the dissolution, which are more favourable in pyrrolidinium cations. This is evidence that solute-solvent interactions are not necessarily dominated by cation $-\pi$ components, and that van der Waals interactions of the alkyl groups with the aromatic solute play a significant role. The RDF of anions with naphthalene for the $\left[\mathrm{C}_{4} \mathrm{C}_{1}\right.$ pyrr $]\left[\mathrm{Ntf}_{2}\right]$ and $\left[\mathrm{C}_{4} \mathrm{C}_{1} \mathrm{im}\right]\left[\mathrm{Ntf}_{2}\right]$ ionic liquids are presented in Fig. S4.2 (ESI $\dagger$ ) and no significant differences were observed.

The RDFs of naphthalene in ILs composed of $\left[\mathrm{C}_{4} \mathrm{C}_{1} \mathrm{im}\right]^{+}$ cations combined with $\left[\mathrm{Ntf}_{2}\right]^{-}$or $\left[\mathrm{C}(\mathrm{CN})_{3}\right]^{-}$show no significant differences (Fig. S4.3 and S4.4, ESI $\dagger$ ). This indicates that the two types of anions are found at similar distances in the solvation shell of naphthalene. The RDFs of naphthalene in $\left[\mathrm{C}_{4} \mathrm{C}_{1} \mathrm{im}\right]\left[\mathrm{Ntf}_{2}\right]$ and $\left[\mathrm{C}_{10} \mathrm{C}_{1} \mathrm{im}\right]\left[\mathrm{Ntf}_{2}\right]$ (Fig. S4.5 and S4.6, ESI $\dagger$ ) indicate that the length of the alkyl chain does not substantially affect the organisation of the ion cores around naphthalene. To better understand the positioning of the alkyl side chains around the solute, we carried out detailed RDF and SDF analyses between the pairs composed of the naphthalene central atoms and the atoms of type CS (methylene carbons of the chain except the two closer to the positively charged N, as identified in Fig. 1). The RDFs are shown in Fig. S4.1 (ESI $\dagger$ ). As discussed previously, the side alkyl chain of $\left[\mathrm{C}_{4} \mathrm{C}_{1}\right.$ pyrr $]\left[\mathrm{Ntf}_{2}\right]$ was found closer to naphthalene than that of $\left[\mathrm{C}_{4} \mathrm{C}_{1} \mathrm{im}\right]\left[\mathrm{Ntf}_{2}\right]$, which is also seen in the SDFs of Fig. 7. The long alkyl chain of $\left[\mathrm{C}_{10} \mathrm{C}_{1} \mathrm{im}\right]\left[\mathrm{Ntf}_{2}\right]$ occupies the regions between the preferred positions of the cation head groups (above and below the ring) and of the anion (on the equator) with successive CS atoms 


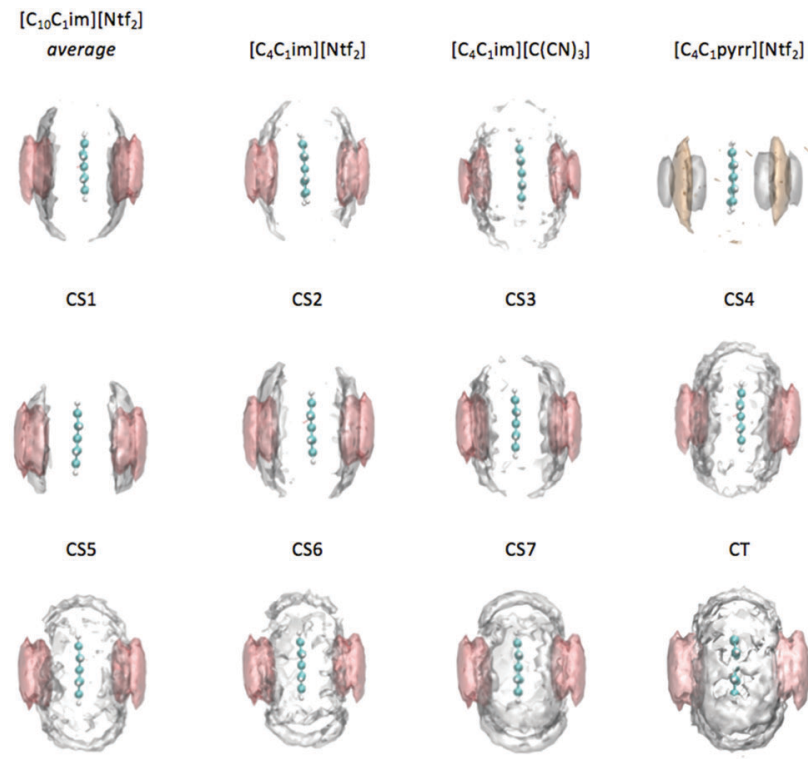

Fig. 7 Spatial distribution functions of atoms of the alkyl side chain of imidazolium or pyrrolidinium cations around naphthalene. Isodensity surfaces for CR atoms are in red, for $\mathrm{N}$ in orange and for CS/C2 in grey (atom type acronyms as in Fig. 1). The second and third rows present the SDFs of the successive $\mathrm{CS}$ atoms in $\left[\mathrm{C}_{10} \mathrm{C}_{1} \mathrm{im}\right]^{+}$.

found further away from the cation head groups (two bottom rows of Fig. 7).

\section{Spectroscopic results}

IR spectroscopic data are listed in Table 4, namely the wavenumbers of the main infrared (IR) bands identified in the differential spectra of three PAHs in different solvents, including the four ILs discussed in the previous sections. All differential spectra were obtained after subtraction of the solution spectra from the corresponding pure solvent spectra. The regions with overlapping PAH and IL bands were not considered. The behaviour of PAHs dissolved in ILs was compared with that of the same PAHs dissolved in different molecular liquids. Three non-protic, nonpolar solvents were considered: tetrachloromethane, $n$-decane and benzene.

The two strongest bands of naphthalene are observed at ca. 790 and $480 \mathrm{~cm}^{-1}$. They are respectively attributed to $\mathrm{CH}$ out-of-plane bending and skeletal (CCC) out-of-plane bending vibrations. ${ }^{73}$ For anthracene and pyrene, the two most intense

Table 4 Wavenumbers of the main infrared bands of three PAHs dissolved in molecular or IL solvents

\begin{tabular}{|c|c|c|c|c|c|c|}
\hline \multirow[b]{2}{*}{ Solvents } & \multicolumn{2}{|c|}{ Naphthalene } & \multicolumn{2}{|c|}{ Anthracene } & \multicolumn{2}{|c|}{ Pyrene } \\
\hline & $\tilde{\nu} / \mathrm{cm}^{-}$ & & $\tilde{\nu} / \mathrm{cm}^{-}$ & & $\tilde{\nu} / \mathrm{cm}^{-}$ & \\
\hline Nominal & 790 & 480 & 885 & 735 & 845 & 715 \\
\hline$n$-Decane & 781.5 & 475.1 & 876.4 & - & 840.8 & 710.5 \\
\hline $\mathrm{CCl}_{4}$ & - & 475.6 & 878.4 & - & 843.0 & 710.5 \\
\hline Benzene & 784.3 & 476.9 & 882.4 & 724.6 & 842.2 & 712.1 \\
\hline$\left[\mathrm{C}_{10} \mathrm{C}_{1} \mathrm{im}\right]\left[\mathrm{Ntf}_{2}\right]$ & 787.0 & 479.0 & 883.8 & 733.5 & 847.6 & 714.3 \\
\hline$\left[\mathrm{C}_{4} \mathrm{C}_{1} \mathrm{im}\right]\left[\mathrm{C}(\mathrm{CN})_{3}\right]$ & 791.7 & 479.9 & 887.1 & 735.8 & 849.8 & 715.3 \\
\hline$\left[\mathrm{C}_{4} \mathrm{C}_{1} \mathrm{im}\right]\left[\mathrm{Ntf}_{2}\right]$ & 790.6 & 479.7 & 887.8 & 735.1 & 850.4 & 715.8 \\
\hline$\left[\mathrm{C}_{4} \mathrm{C}_{1} \mathrm{pyrr}\right]\left[\mathrm{Ntf}_{2}\right]$ & 791.1 & 480.0 & 886.8 & 735.8 & 851.2 & 716.0 \\
\hline
\end{tabular}

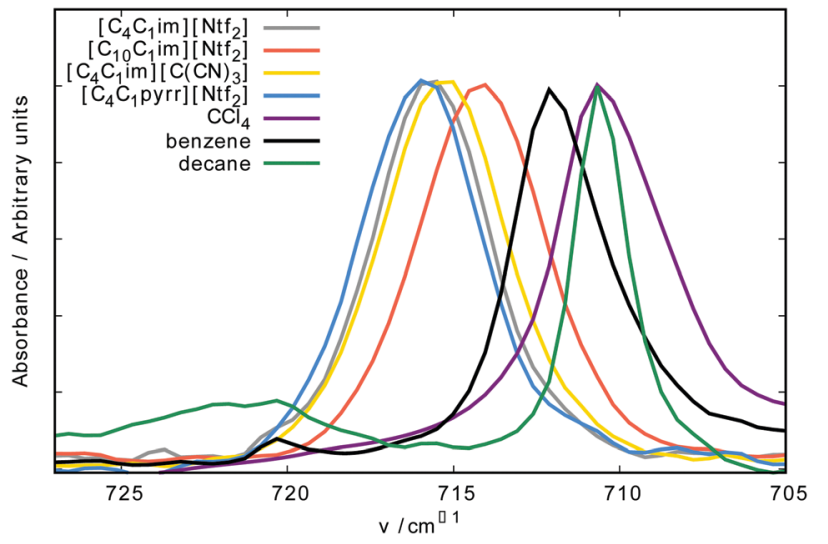

Fig. 8 Differential infrared spectra of pyrene dissolved in four ILs and three classical solvents.

bands are at around 845 and $715 \mathrm{~cm}^{-1}$ and 885 and $735 \mathrm{~cm}^{-1}$, respectively, and are assigned to two $\mathrm{CH}$ out-of-plane bending modes. $^{74,75}$

The lowest IR wavenumbers presented in Table 4 correspond to the dissolution of the three PAHs in $n$-decane. Among the three molecular solvents, the order is generally $\tilde{\nu}_{n \text {-decane }} \leq$ $\tilde{\nu}_{n \mathrm{CCl}_{4}}<\tilde{\nu}_{\text {benzene }}$, evidencing the influence of aromaticity of the solvent on the molecular vibration of PAHs. On the other hand, the four IL solvents induce shifts to even higher IR wavenumbers than the three molecular solvents. The solvent-induced shifts of the $715 \mathrm{~cm}^{-1}$ band of pyrene presented in Fig. 8 are good examples of the above-mentioned trends.

The observed shifts are obviously correlated to the influence of the solvation shells on the out-of-plane motions of the PAH molecules: "softer" environments generated by weaker and more disperse PAH-solvent interactions in less structured solvents should cause out-of-plane bending modes with lower wavenumbers; "firmer" and more structured environments should trigger out-of-plane motions with higher wavenumbers. Two particularly interesting facts can be surmised from Table 4 and Fig. 8 as far as the IL solvents are concerned: (i) no significant shifts could be observed while comparing the spectra of the different PAHs in $\left[\mathrm{C}_{4} \mathrm{C}_{1} \mathrm{im}\right]\left[\mathrm{Ntf}_{2}\right]$, $\left[\mathrm{C}_{4} \mathrm{C}_{1} \mathrm{im}\right]\left[\mathrm{C}(\mathrm{CN})_{3}\right]$ and $\left[\mathrm{C}_{4} \mathrm{C}_{1}\right.$ pyrr $]\left[\mathrm{Ntf}_{2}\right]$. This is compatible with the simulation of the RDF results (Fig. 6 and Fig. S4.2-S4.4, ESI $\dagger$ ) where it can be seen that changing the anion from $\left[\mathrm{Ntf}_{2}\right]$ to $\left[\mathrm{C}(\mathrm{CN})_{3}\right]$ or the cation from $\left[\mathrm{C}_{4} \mathrm{C}_{1} \mathrm{im}\right]$ (aromatic) to $\left[\mathrm{C}_{4} \mathrm{C}_{1}\right.$ pyrr $]$ (non-aromatic) does not modify significantly the positions of the ions with respect to naphthalene. (ii) The spectra of the different PAHs in $\left[\mathrm{C}_{10} \mathrm{C}_{1} \mathrm{im}\right]\left[\mathrm{Ntf}_{2}\right]$ are always shifted to lower wavenumbers when compared with spectra based on other IL solvents. Fig. 7, Fig. S4.5 and S4.6 (ESI $\dagger$ ) show that the decyl chains of $\left[\mathrm{C}_{10} \mathrm{C}_{1} \mathrm{im}\right]\left[\mathrm{Ntf}_{2}\right]$ envelope the naphthalene molecules quite effectively. Such an aliphatic cocoon, dominated by dispersion forces, contributes to a "softer" solvation shell and causes the aforementioned shifts to lower wavenumbers.

\section{Conclusions}

One important point that was consistently observed in our different measurements and calculations is that van der Waals 
interactions between alkyl side chains and groups, both in imidazolium and in pyrrolidinium cations, play a significant role in the solvation of PAHs. This is clearly seen in the higher solubility and lower enthalpy of dissolution in $\left[\mathrm{C}_{10} \mathrm{C}_{1} \mathrm{im}\right]\left[\mathrm{Ntf}_{2}\right]$ when compared with all other studied ILs. Although interactions between the imidazolium ring and the $\pi$ system of the PAHs are present - with cations found above and below the aromatic planes - the role of the side chains is significant. It was also interesting to see that in pyrrolidinium cations, alkyl groups appear intercalated between the positive $\mathrm{N}$ atom and PAHs, including the alkyl side chain. With this component of "non-polar" solvation, pyrrolidinium ILs appear as better solvents, mainly for energetic reasons, for $\mathrm{PAH}$ compared to the equivalent imidazolium ILs. These different elements all converge to a picture of a significant "non-polar" component in the solvation ${ }^{21}$ of PAHs in ILs.

Among the anions that were studied in more detail here, $\left[\mathrm{C}(\mathrm{CN})_{3}\right]^{-}$, a planar anion smaller than $\left[\mathrm{Ntf}_{2}\right]^{-}$, leads to higher solubility and lower enthalpies of dissolution.

Some observed features were common to all solvents studied, namely the ordering of the anions around the aromatic solutes, with cations above and below the plane and anions located mostly around the equator, interacting with the hydrogenated edges of the PAHs. This is a well-known feature of the solvation shells of ILs around aromatic compounds.

The different experimental and computational methods used in this work each provided a partial view on the solvation phenomena, but together the different pieces of information were complementary. Simulation methods, although not reaching quantitative agreement in solubility or thermodynamic quantities of solvation, do reproduce correctly the dependence of the thermodynamic quantities on the molecular structure of the ions. Besides, the microscopic structural information on the ordering of ions in the solvation shells is precious. Molecular simulation is a very useful method, providing important microscopic insights and we are confident of its ability to predict trends.

\section{Conflicts of interest}

There are no conflicts to declare.

\section{Acknowledgements}

This work was supported by the Agence Nationale de la Recherche project CLINT ANR-12-IS10-003.

\section{Notes and references}

1 J. N. Coleman, Adv. Funct. Mater., 2009, 19, 3680-3695.

2 F. Torrisi, T. Hasan, W. Wu, Z. Sun, A. Lombardo, T. S. Kulmala, G.-W. Hsieh, S. Jung, F. Bonaccorso, P. J. Paul, D. Chu and A. C. Ferrari, ACS Nano, 2012, 6, 2992-3006.

3 B. K. Price, J. L. Hudson and J. M. Tour, J. Am. Chem. Soc., 2005, 127, 14867-14870.

4 T. Welton, Chem. Rev., 1999, 99, 2071-2084.
5 J. N. Canongia Lopes and A. A. H. Padua, J. Phys. Chem. B, 2006, 110, 3330-3335.

6 V. Nicolosi, M. Chhowalla, M. G. Kanatzidis, M. S. Strano and J. N. Coleman, Science, 2013, 340, 1226419.

7 S. Ravula, S. N. Baker, G. Kamath and G. A. Baker, Nanoscale, 2015, 7, 4338-4353.

8 T. Fukushima, A. Kosaka, Y. Ishimura, T. Yamamoto, T. Takigawa, N. Ishii and T. Aida, Science, 2003, 300, 2072-2074.

9 M. Matsumoto, Y. Saito, C. Park, T. Fukushima and T. Aida, Nat. Chem., 2015, 7, 730-736.

10 J. Le Bideau, L. Viau and A. Vioux, Chem. Soc. Rev., 2011, 40, 907-925.

11 M. Armand, F. Endres, D. R. Macfarlane, H. Ohno and B. Scrosati, Nat. Mater., 2009, 8, 621-629.

12 I. Ahmad, U. Khan and Y. K. Gun'ko, J. Mater. Chem., 2011, 21, 16990-16996.

13 T. Kim, G. Jung, S. Yoo, K. S. Suh and R. S. Ruoff, ACS Nano, 2013, 7, 6899-6905.

14 K. Müllen, Angew. Chem., 2015, 127, 10040-10042.

15 G. R. Jenness, O. Karalti and K. D. Jordan, Phys. Chem. Chem. Phys., 2010, 12, 6375-6381.

16 M. Hughes, Y. Hernandez, D. Aherne, L. Doessel, K. Müllen, B. Moreton, T. W. White, C. Partridge, G. Costantini, A. Shmeliov, M. Shannon, V. Nicolosi and J. N. Coleman, J. Am. Chem. Soc., 2012, 134, 12168-12179.

17 Y. Wu and N. R. Aluru, J. Phys. Chem. B, 2013, 117, 8802-8813.

18 J. Szala-Bilnik, M. F. Costa Gomes and A. A. H. Padua, J. Phys. Chem. C, 2016, 120, 19396-19408.

19 T. Fukushima and T. Aida, Chemistry, 2007, 13, 5048-5058.

20 M. Tunckol, J. Durand and P. Serp, Carbon, 2012, 50, 4303-4334.

21 R. Peng, Y. Wang, W. Tang, Y. Yang and X. Xie, Polymers, 2013, 5, 847-872.

22 A. Di Crescenzo, D. Demurtas, A. Renzetti, G. Siani, P. De Maria, M. Meneghetti, M. Pratod and A. Fontana, Soft Matter, 2009, 5, 62-66.

23 Y. Liu, L. Yu, S. Zhang, J. Yuan, L. Shi and L. Zheng, Colloids Surf., A, 2010, 359, 66-70.

24 F. Lu, S. Zhang and L. Zheng, J. Mol. Liq., 2012, 173, 42-46. 25 M. Lotya, Y. Hernandez, P. J. King, R. J. Smith, V. Nicolosi, L. S. Karlsson, F. M. Blighe, S. De, Z. Wang, I. T. McGovern, G. S. Duesberg and J. N. Coleman, J. Am. Chem. Soc., 2009, 131, 3611-3620.

26 J. N. Coleman, Acc. Chem. Res., 2013, 46, 14-22.

27 Q. Dou, M. L. Sha, H. Y. Fu and G. Z. Wu, J. Phys.: Condens. Matter, 2011, 23(17), 175001.

28 J. Vatamanu, O. Borodin and G. D. Smith, J. Am. Chem. Soc., 2010, 132, 14825-14833.

29 J. Vatamanu, O. Borodin, D. Bedrov and G. D. Smith, J. Phys. Chem. C, 2012, 116, 7940-7951.

30 F. Huo and Z. Liu, Mol. Simul., 2015, 41, 271-280.

31 A. Ghoufi, A. Szymczyk and P. Malfrey, Sci. Rep., 2016, 6, 28518.

32 G. Feng, D. Jiang and P. T. Cummings, J. Chem. Theory Comput., 2012, 8, 1058-1063. 
33 X. Wang, P. F. Fulvio, G. A. Baker, G. M. Veith, R. R. Unocic, S. M. Mahurin, M. Chib and S. Dai, Chem. Commun., 2010, 46, 4487-4489.

34 R. Baria, G. Tamasb, F. Irina, A. J. A. Aquinob, M. J. Greena and E. L. Quitevis, Colloids Surf., A, 2014, 463, 63-69.

35 G. Kamath and G. A. Baker, Phys. Chem. Chem. Phys., 2012, 14, 7929-7933.

36 S. Baldelli, J. Bao, W. Wu and S. Pei, Chem. Phys. Lett., 2011, 516, 171-173.

37 Y. Shim and H. J. Kim, ACS Nano, 2009, 3, 1693-1702.

38 J. M. P. França, F. Reis, S. I. C. Vieira, M. J. V. Lourenço, F. J. V. Santos, C. A. Nieto de Castro and A. A. H. Pádua, J. Chem. Thermodyn., 2014, 79, 248-257.

39 J. Wang, H. Chu and Y. Li, ACS Nano, 2008, 2, 2540-2546.

40 D. Han and K. H. Row, Molecules, 2010, 15, 2405-2426.

41 X. Han and D. W. Armstrong, Acc. Chem. Res., 2007, 40, 1079-1086.

42 M. German-Hernandez, V. Pino, J. L. Anderson and A. M. Afonso, J. Chromatogr. A, 2012, 1227, 29-37.

43 C. Yao and J. L. Anderson, Anal. Bioanal. Chem., 2009, 395, 1491-1502.

44 C. Yao, W. R. Pitner and J. L. Anderson, Anal. Chem., 2009, 81, 5054-5063.

45 M. German-Hernandez, V. Pino, J. L. Anderson and A. M. Afonso, Talanta, 2011, 85, 1199-1206.

46 M. S. El-Shahawi, A. Hamza, A. S. Bashammakh and W. T. Al-Saggaf, Talanta, 2010, 80, 1587-1597.

47 P. Kodali and A. M. Stalcup, J. Liq. Chromatogr. Relat. Technol., 2014, 37, 893-906.

48 M. Rezaee, Y. Yamini and M. Faraji, J. Chromatogr. A, 2010, 1217, 2342-2357.

49 Y. Hsieh, P. Huang, I. Sun, T. Whang, C. Hsu, H. Huang and C. Kuei, Anal. Chim. Acta, 2006, 557, 321-328.

50 J. Liu, Y. Chi and G. Jiang, J. Sep. Sci., 2005, 28, 87-91.

51 E. Aguilera-Herrador, R. Lucena, S. Cardenas and M. Valcarcel, TrAC, Trends Anal. Chem., 2010, 29, 602-616.

52 Y. Meng and J. L. Anderson, J. Chromatogr. A, 2010, 1217, 6143-6152.

53 J. Liu, G. Jiang, Y. Chi, Y. Cai, Q. Zhou and J. Hu, Anal. Chem., 2003, 75, 5870-5876.
54 S. U. Mokhtar, S.-T. Chin, R. Vijayaraghavan, D. R. MacFarlane, O. H. Drummerd and P. J. Marriott, Green Chem., 2015, 17, 573-581.

55 W. Ho, Y. Hsieh, W. Lin, C. L. Kao, P. Huang, C. Yeh, C. Pane and C. Kuei, Anal. Methods, 2010, 2, 455-457.

56 J. Maszkowska, E. Synak, A. Fabiańska, M. Caban, S. Stolte, P. Husson, M. F. Costa Gomes, R. Synak and P. Stepnowski, Anal. Bioanal. Chem., 2015, 407, 3531-3536.

57 R. Kaliszana, M. P. Marszalla, M. J. Markuszewskia, T. Baczeka and J. Pernak, J. Chromatogr. A, 2004, 1030, 263-271.

58 J. Liu, G. Jiang, Y. Chi, Y. Cai, Q. Zhou and J. Hu, Anal. Chem., 2003, 75, 5870-5876.

59 D. Wagle, G. Kamath and G. A. Baker, J. Phys. Chem. C, 2013, 117, 4521-4532.

60 J. M. Andanson, A. A. H. Padua and M. F. C. Gomes, Chem. Commun., 2015, 51, 4485-4487.

61 W. L. Jorgensen and D. L. Severance, J. Am. Chem. Soc., 1990, 112, 4768-4774.

62 J. N. Canongia Lopes, J. Deschamps and A. A. H. Padua, J. Phys. Chem. B, 2004, 108, 2038-2047.

63 J. N. Canongia Lopes and A. A. H. Padua, Theor. Chem. Acc., 2012, 131, 1129-1139.

64 C. Schröder, Phys. Chem. Chem. Phys., 2012, 14, 3089.

65 E. Marin-Rimoldi, J. K. Shah and E. J. Maginn, Fluid Phase Equilib., 2016, 407, 117-125.

66 B. L. Bhargava and S. Balasubramanian, J. Chem. Phys., 2007, 127, 114510.

67 A. A. H. Padua, fftool, github.com/agiliopadua/fftool.

68 L. Martínez, R. Andrade, E. G. Birgin and J. M. Martínez, J. Comput. Chem., 2009, 30, 2157-2164.

69 S. J. Plimpton, J. Comput. Phys., 1995, 117, 1-19.

70 T. C. Beutler, A. E. Mark, R. C. van Schaik, P. R. Gerber and W. F. van Gunsteren, Chem. Phys. Lett., 1994, 222, 529-539.

71 K. Shimizu, M. F. Costa Gomes, A. A. H. Padua, L. P. N. Rebelo and J. N. C. Lopes, J. Phys. Chem. B, 2009, 113, 9894-9900.

72 C. G. Hanke, A. Johansson, J. B. Harper and R. M. LyndenBell, Chem. Phys. Lett., 2003, 274, 85-90.

73 A. L. McClellan and G. C. Pimentel, J. Chem. Phys., 1955, 23, 245.

74 S. Califano and G. Abbondanza, J. Chem. Phys., 1963, 39, 1016.

75 S. Califano, J. Chem. Phys., 1962, 36, 903. 